\title{
Epidemiology of Helicobacter pylori and gastric cancer
}

\author{
SHOGO KiKUCHI \\ Department of Public Health, Aichi Medical University School of Medicine, 21 Karimata, Yazako, Nagakute-cho, Aichi 480-1195, Japan
}

\begin{abstract}
Findings in epidemiological studies of the relationship between Helicobacter pylori and gastric cancer have been inconsistent: many studies have yielded a positive relationship, whereas several studies have shown no relationship. The inconsistency arises because of the occurrence of seroreversion during the period between the time that $H$. pylori exerts a carcinogenic effect and the time of blood sampling. When this seroreversion is taken into account, there is an epidemiologically positive association between $H$. pylori status and the risk for gastric cancer. In addition to the epidemiological evidence, experimental studies using Mongolian gerbils have shown that $H$. pylori infection elevates the risk for gastric cancer. It is concluded that $\boldsymbol{H}$. pylori is a causal factor for gastric cancer. In the creation of preventive strategies against gastric cancer by the eradication of $\mathrm{H}$. pylori, determination of the time at which $H$. pylori plays a role as a carcinogen is important. Three hypotheses have been proposed in regard to this timing: that $H$. pylori infection in childhood or the teenage years acts as a factor that produces precancerous lesions with irreversible damage in the gastric mucosa, that in adulthood it acts as an initiator, and also in adulthood, that it acts as a promoter. As these hypotheses are not mutually exclusive, the extent to which each hypothesis plays a part in explaining gastric carcinogenesis should be evaluated. Only a small proportion of subjects infected with $\boldsymbol{H}$. pylori have gastric cancer during their lifetime. Interleukin-1 polymorphism, a host factor, and CagA, a virulence factor of $\boldsymbol{H}$. pylori, are suspected to be risk factors for gastric cancer in subjects with $H$. pylori infection. Dietary factors, especially vitamin $\mathrm{C}$, and patterns of precancerous lesions also seem to influence the relationship between $H$. pylori and gastric cancer. $H$. pylori seems to reduce the risk for esophageal and for some gastric cardia adenocarcinomas. This finding, as well as determination of the time at which $H$. pylori exerts this preventive effect, should be considered in the creation of preventive strategies against gastric cancer that target the eradication of $\mathrm{H}$. pylori.
\end{abstract}

Offprint requests to: S. Kikuchi

Received: June 1, 2001 / Accepted: October 16, 2001
Key words Prevention for gastric cancer · Helicobacter pylori . Esophageal adenocarcinoma

\section{Introduction}

Helicobacter pylori is a gram negative bacillus that lives in the mucus of the human stomach. H. pylori, which was discovered in 1982 [1], produces carbon dioxide and ammonia from urea by the action of urease [2]. The ammonia elevates the $\mathrm{pH}$ of the mucus so that this bacillus can live there.

In this review article, studies of the relationship between H. pylori and gastric cancer to date are reviewed, and differences in the relationship depending on histopathological type (diffuse/intestinal), stage (early/advanced), the location of the cancer (cardia/noncardia), and CagA status are discussed. Problems in the creation of a preventive strategy against gastric cancer by the eradication of $H$. pylori are also discussed.

\section{Epidemiology of Helicobacter pylori}

Helicobacter pylori usually continues to live in the stomach once infection has occurred [3]. In Japan, prevalence of $H$. pylori increases with age [4]. It is believed that most $H$. pylori infection occurs in childhood $[5,6]$. Acquisition of $H$. pylori is related to sanitary conditions, such as living conditions [7-9], water supply, and sewerage $[10,11]$. The age-dependent prevalence of $H$. pylori in Japan may be a result of the gradual progress in sanitary conditions that has taken place in Japan since 1950. Even in adulthood, a family history of stomach diseases and sibship size showed an association with the prevalence of $H$. pylori [6]. The prevalence of $H$. pylori is also related to periods spent in nursery school [9]. Child-to-child infection may be the main infection route of $H$. pylori. In regard to world distribution, the pre- 
Table 1. Prospective studies evaluating the relationship between Helicobacter pylori and gastric cancer

\begin{tabular}{|c|c|c|c|c|c|c|}
\hline \multirow[b]{2}{*}{ Authors } & \multirow[b]{2}{*}{ Place } & \multirow{2}{*}{$\begin{array}{l}\text { Age, in years } \\
\text { (mean) }\end{array}$} & \multirow{2}{*}{$\begin{array}{l}\text { Follow-up } \\
\text { (years) }\end{array}$} & \multirow{2}{*}{$\begin{array}{c}\text { Odds ratio } \\
(95 \% \mathrm{CI})\end{array}$} & \multicolumn{2}{|c|}{ Seroprevalence } \\
\hline & & & & & Patients & Control \\
\hline Forman et al. [22] & England & $41-63(54)$ & 6.0 & $2.8(1.0-8.0)$ & $69 \%$ & $47 \%$ \\
\hline Nomura et al. [23] & Hawaii, USA & $46-65(59)$ & 13.0 & $6.0(2.1-17.3)$ & $94 \%$ & $76 \%$ \\
\hline Parsonnet et al. [24] & California, USA & (54) & 14.2 & $3.6(1.8-7.3)$ & $84 \%$ & $61 \%$ \\
\hline Webb et al. [25] & Shanghai, China & $48-69(61)$ & 2.4 & $0.9(0.6-1.5)$ & $54 \%$ & $56 \%$ \\
\hline Lin et al. [26] & Taiwan & $(63)$ & 3.0 & $1.6(0.7-2.6)$ & $69 \%$ & $59 \%$ \\
\hline Watanabe et al. [27] & Kyoto, Japan & & 3.2 & $3.4(1.2-9.9)$ & $91 \%$ & $76 \%$ \\
\hline Aromaa et al. (IgA) [28] & Finland & $(62)$ & 13.0 & $2.5(1.1-5.6)$ & $89 \%$ & $76 \%$ \\
\hline
\end{tabular}

CI, Confidence interval

Table 2. Case-control studies evaluating the relationship between Helicobacter pylori and gastric cancer

\begin{tabular}{|c|c|c|c|c|c|}
\hline \multirow[b]{2}{*}{ Authors } & \multirow[b]{2}{*}{ Place } & \multirow{2}{*}{$\begin{array}{l}\text { Age, in years } \\
\text { (mean) }\end{array}$} & \multirow{2}{*}{$\begin{array}{c}\text { Odds ratio } \\
(95 \% \mathrm{CI})\end{array}$} & \multicolumn{2}{|c|}{ Seroprevalence } \\
\hline & & & & Patients & Control \\
\hline Hasson et al. [29] & Sweden & $\leqq 79(67)$ & $2.6(1.4-5.0)$ & $80 \%$ & $61 \%$ \\
\hline Asaka et al. [30] & Hokkaido, Japan & $(60)$ & $2.6(1.5-4.3)$ & $88 \%$ & $75 \%$ \\
\hline Kikuchi et al. [31] & Tokyo, Japan & $20-39$ (34) & $13.3(5.3-35.6)$ & $89 \%$ & $39 \%$ \\
\hline Kikuchi et al. [32] & Tokyo, Japan & $20-69$ & & (See Table 3) & \\
\hline Rudi et al. [33] & Germany & $26-83(60)$ & $1.4(0.8-2.4)$ & $59 \%$ & $51 \%$ \\
\hline Fukuda et al. [34] & Tokyo, Japan & $23-83$ (57) & $1.0(0.7-1.5)$ & $76 \%$ & $74 \%$ \\
\hline
\end{tabular}

valence of $H$. pylori is low in Western and Northern Europe and North America and high in Asia and Eastern Europe [12].

Rod and coccoid forms of $H$. pylori have been seen in dental plaque [13]. In an experimental study, volunteers with $H$. pylori infection were given a cathartic and an emetic. H. pylori was cultured from all vomitus samples, $38 \%$ of air samples during vomiting, $19 \%$ of saliva samples before emesis, $56 \%$ of saliva samples after emesis, no normal stools, and $22 \%$ of induced stools [14]. In attempts to show that feco-oral infection is the main infection route of $H$. pylori, the association between $H$. pylori status and presence antibody for hepatitis A virus, the infection route of which is known to be feco-oral, has been investigated, but results have been controversial $[15,16]$. In Japan, no association was observed between $H$. pylori status and hepatitis A virus antibody [17], although this does not necessarily deny feco-oral infection. Oral-oral, that is, gastro-oral, infection is suspected, rather than feco-oral infection [18].

\section{Causal relationship between $\boldsymbol{H}$. pylori and gastric cancer}

Initially, the relationship between $H$. pylori and gastric cancer was investigated epidemiologically, with most of the studies being serological. Ecological studies showed that the prevalence of $H$. pylori was positively related to gastric cancer mortality $[12,19]$. In Japan, the preva- lence of $H$. pylori differs among areas and is related to gastric cancer mortality [20,21]. The association between gastric cancer and $H$. pylori was shown by prospective studies [22-28] in which odds ratios were 0.9 to 6.0 (Table 1). Several case-control studies were also carried out. The results of the studies were not consistent (Table 2) [29-34]. Some of them showed a positive association, but some studies found no association, or nonsignificant results. A few cohort studies have shown no association between gastric cancer and $H$. pylori. Thus, to date the findings of the epidemiological studies have been inconsistent. Seroconversion and seroreversion (negative-to-positive and positive-to-negative changes in serology, respectively) in accordance with the stages of progression of gastric cancer can explain the inconsistencies.

\section{Seroconversion and seroreversion}

Most epidemiological studies that evaluated the relationship between $H$. pylori and gastric cancer determined $H$. pylori status serologically. In case-control studies, it is possible that seroconversion and seroreversion occurred during the incubation period, i.e., during the period between the time at which $H$. pylori exerts a carcinogenic effect and the time of diagnosis of cancer [32]. New infections can occur in both cases and control subjects during the incubation period, bringing about seroconversion in the subjects. Gastric mucosa with severe atrophy with intestinal metaplasia is less pleasant 
for $H$. pylori to live in, and the bacillus sometimes disappears from the mucosa [35]. While seroreversion could occur in control subjects because of advanced atrophy, it is expected to be much more rare than in gastric cancer patients. H. pylori causes mucosal atrophy and intestinal metaplasia [36], and the seroprevalence of $H$. pylori was often higher in gastric cancer patients than in control subjects. Seroreversion does occur in healthy older subjects [37,38]. As atrophy of the gastric mucosa progresses with time, its effect appears to be greater in older subjects [39].

\section{Early and advanced gastric cancers}

A few studies, most of which are Japanese, have compared the effect of $H$. pylori in early and advanced gastric cancers. H. pylori showed a stronger relationship with early cancer than with advanced cancer [30-32]. Many other studies, including cohort studies, have not mentioned the stage of progression of gastric cancer.

Seroreversion may occur as a result of the natural progression of gastric cancer rendering the gastric mucosa inhospitable to H. pylori [39], or through weakening of the immune reaction [40]. It takes from 6 months to 7 years for early cancer to progress to advanced cancer [41]. The incubation period of $H$. pylori infection is longer in advanced cancer patients than in early cancer patients, and this may cause more frequent seroreversion $[42,43]$ in advanced cancer patients. These mechanisms are consistent with the weaker relationship between advanced gastric cancer and $H$. pylori. When age is considered, the weaker relationship of $H$. pylori with advanced cancer is observed more frequently among those aged over 50 years [32].

\section{Intestinal type and diffuse type}

Intestinal type gastric cancer, which is more differentiated than diffuse type cancer, is usually associated with atrophy of the gastric mucosa [44] and is thought to develop in mucosa with atrophy. Diffuse type cancer often develops in mucosa without atrophy. H. pylori is known to cause atrophic gastritis. Therefore, it was believed, at first, that $H$. pylori elevated the risk of intestinal type cancer, but not the risk of diffuse type cancer. A few microscopic studies yielded a closer association of $H$. pylori with intestinal type cancer [45,46].

However, many serological studies have shown that both diffuse type and intestinal type cancers are related to $H$. pylori status $[23,24,29,31,47]$. There appears to be little difference in the seroprevalence of $H$. pylori between the two types of cancers, even after adjusting for age [32]. In terms of a relationship to H. pylori, no difference seems to exist between diffuse type and intestinal type cancers. The results of the microscopic studies may have reflected the characteristic that diffuse type cancer is less hospitable to $H$. pylori than intestinal type [48], and H. pylori was less frequently observed in diffuse type cancer tissue.

\section{Explanation for the inconsistencies among the epidemiological studies}

We consider that seroconversion and seroreversion, especially the latter, may account for the inconsistencies among epidemiological studies that have assessed the relationship between $H$. pylori and gastric cancer. In most countries, except for Japan, screening programs for gastric cancer have not been put into practice [49]. In countries other than Japan, gastric cancer patients are more likely to have advanced disease. Actually, most epidemiological studies to date, with a few exceptions [30-32], have not mentioned the stage of progression in their case subjects. Case-control studies that show lack of a relationship between $H$. pylori and gastric cancer would be expected to have examined mainly older subjects and subjects with advanced cancer [32], so that seroreversion would have occurred during the incubation period. Even in prospective studies, if the observation period $[25,26]$ is short, it is possible that the tumor in the stomach may have existed at the baseline point of the study and that seroreversion may have occurred before the baseline point at which blood sampling was performed. Thus, the inconsistencies among the findings of the epidemiological studies may be the result of seroreversion, and it is concluded that there is a consistent relationship between $H$. pylori and gastric cancer.

\section{Causal relationship}

As discussed above, epidemiological studies have shown a relationship between $H$. pylori and gastric cancer. Five points, that is, strength of association, temporality between the cause and the disease, consistent findings among epidemiological studies, specificity, and biological plausibility of the relationship, should be checked for the determination of a causal relationship [50]. A strong relationship between $H$. pylori and gastric cancer, that is, a high odds ratio, has been observed [24,31]. Temporality is confirmed by cohort studies. Temporality is reinforced by the finding that time after the blood sampling (baseline) was positively related to the strength of the relationship [24]. Consistency exists, as mentioned above (i.e., the inconsistent epidemiological findings have been explained). Specificity may be confirmed by noting the high seroprevalence in gastric cancer patients (Tables 1,2). Lack of biological plausibility, however, used to be a drawback when a causal relationship between $H$. pylori and gastric cancer was considered. 
Recently, an animal model of gastric carcinogenesis was established, using the Mongolian gerbil. A study showed that long-term $H$. pylori infection alone caused stomach cancer in the Mongolian gerbil [51], although other studies of the same design have not succeeded in causing stomach cancer. Several studies have shown that $H$. pylori infection markedly increases [52,53], and eradication of $H$. pylori markedly reduces, gastric cancer in the Mongolian gerbil [54]. Thus, it has been established that $H$. pylori plays a part in gastric carcinogenesis.

\section{Preventive strategy against gastric cancer by the eradication of $\boldsymbol{H}$. pylori}

Prevention of gastric cancer by the eradication of $H$. pylori is possible, if $H$. pylori is a causal risk factor. When an effective prevention strategy is considered, determination of the critical timeframe (critical time) during which $H$. pylori produces its carcinogenic effect is important, because the eradication of $H$. pylori after this time would have no preventive effect on the incidence of gastric cancer. Although cancer prevention trials focusing on the eradication of $H$. pylori have already been started, the critical time has not yet been identified. To identify the critical time and the mechanism by which a risk factor operates, it is important to elucidate the relationship between the length of exposure and the magnitude of the effect. As the length of exposure is associated with age, the effect of age on the strength of the relationship provides useful information.

\section{Effect of age on the relationship between $\mathrm{H}$. pylori and gastric cancer}

In the younger Japanese population (those under 40 years of age), a high odds ratio, of 13.3, was shown for the relationship between $H$. pylori and gastric cancer [31]. A meta-analysis reported that the relationship between $H$. pylori and gastric cancer was stronger in a younger population [47]. In subjects from a defined ethnic group from a single region of Japan, a casecontrol study gave similar results (Table 3) [32]; in that study, the level of $H$. pylori antibody was measured in the sera of 787 patients with gastric cancer and 1007 control subjects, aged 20 to 69 years, stratified into several 10-year age classes. No studies to date have reported a stronger relationship in an older population. Thus, the relationship between $H$. pylori and gastric cancer is generally weaker in an older population.

However, the weaker relationship in older populations could be the result of seroreversion in older patients. In order to control for the effect of seroreversion owing to atrophy or cancer, a separate analysis that
Table 3. Odds ratios of association of Helicobacter pylori and gastric cancer in patients stratified by age

\begin{tabular}{lccc}
\hline $\begin{array}{l}\text { Age } \\
\text { (years) }\end{array}$ & $\begin{array}{c}\text { Control } n \\
\text { (positive \%) }\end{array}$ & $\begin{array}{c}\text { Case } n \\
\text { (positive \%) }\end{array}$ & $\begin{array}{c}\text { Odds ratio } \\
(95 \% \text { CI })\end{array}$ \\
\hline $20-29$ & $201(28.4)$ & $4(75.0)$ & $7.58(0.68-$-infinity) \\
$30-39$ & $202(43.1)$ & $36(88.9)$ & $10.58(3.40-36.70)$ \\
$40-49$ & $199(54.3)$ & $156(91.3)$ & $8.85(4.62-17.21)$ \\
$50-59$ & $203(71.4)$ & $262(90.5)$ & $3.79(2.21-6.54)$ \\
$60-69$ & $202(81.2)$ & $329(88.4)$ & $1.77(1.06-2.98)$ \\
\hline
\end{tabular}

From [32]

focused on early diffuse-type cancer was conducted. In early diffuse-type cancer, the odds ratios did not depend on age, but they did depend on age in all other gastric cancers [32]. The weaker relationship in the older population may be a superficial phenomenon because of seroreversion in older patients with gastric cancer. The relationship between $H$. pylori and gastric cancer may not depend on age.

\section{Exposure to $\mathrm{H}$. pylori and risk of gastric cancer}

In developed countries, infection with $H$. pylori mainly occurs before 20 years of age, and infection after 20 years of age is relatively rare $[8,38]$. Thus, older subjects infected with $H$. pylori are likely to have been exposed to the bacillus for a longer period of time. On the other hand, the relationship between $H$. pylori and gastric cancer does not change with age, although it is superficially stronger in younger subjects. Long exposure does not seem to increase the magnitude of $H$. pylori influence on gastric carcinogenesis.

This relationship is markedly different from that between smoking and lung cancer. Studies of the relationship between smoking and lung cancer have shown that the relative risk or odds ratio increases with age; that is, the longer the exposure to smoking, the greater the magnitude of its effect on the incidence of lung cancer $[55,56]$. Hypotheses to explain the mechanisms of and critical time for H. pylori in gastric carcinogenesis have to be consistent with the finding that long exposure does not increase the magnitude of its influence.

\section{Hypotheses for the relationship between length of exposure to $\mathrm{H}$. pylori and magnitude of its influence}

Three hypotheses have been proposed to explain the noncumulative effect of $H$. pylori [32]. The first hypothesis is that, during childhood or the teenage years, $H$. pylori damages the gastric mucosa in such a manner that the damage, which may be a kind of precancerous lesion, remains into adulthood. The second hypothesis is that $H$. pylori has an initiator effect on carcinogenesis, as does a small dose of radiation. The third hypothesis is 
that $H$. pylori acts as a promoter, reducing the threshold for carcinogenesis.

According to the first hypothesis, continuous infection with $H$. pylori during childhood or the teenage years may irreversibly harm the gastric mucosa. In this case, the critical time is childhood or the teenage years. Eradication should be conducted in childhood or early in the teenage years, because eradication after the irreversible harm has been produced does not prevent carcinogenesis at all. This hypothesis is supported by an American study of Japanese-Americans, in which those suspected of childhood infection with $H$. pylori had a higher risk of gastric cancer [57]. If the diagnosis of the irreversible harm so hypothesized becomes possible, the risk for gastric cancer of each subject could be evaluated much more precisely.

According to the second hypothesis, H. pylori may increase the risk of carcinogenesis while the infection continues, but the effects are not cumulative, and may be important in adulthood. Inflammation provoked by $H$. pylori may damage the DNA of the mucosal cells. Thus, any period of continuous infection could be the critical time, and, in the presence of other factors, especially promoters, the infection may cause carcinogenesis. If this is so, then eradication should be conducted early in adulthood, or before that, because eradication after the initiation of carcinogenesis has no preventive effect.

According to the third hypothesis, H. pylori may promote gastric carcinogenesis while the infection continues, and the effect of $H$. pylori may be completed during a short period. Inflammation provoked by $H$. pylori accelarates the turnover of mucosal cells, which may promote carcinogenesis. Any period of continuous infection could be the critical time, and the promoter effects of $H$. pylori may be important in adulthood when most initiation is expected to occur. This hypothesis is supported by a Japanese study in which the eradication of $H$. pylori prevented the subsequent development of gastric cancer after endoscopic resection [58]. A recent experimental study, using Mongolian gerbils, has suggested that $H$. pylori may exert a promoter effect in gastric carcinogenesis [53]. If this is so, then $H$. pylori eradication at any time may reduce the risk of gastric cancer.

These hypotheses are not mutually exclusive; that is, two or three of these hypotheses could be true. Whether or not each hypothesis is true should be confirmed, and the extent to which each hypothesis plays a part in explaining gastric carcinogenesis should be evaluated.

\section{Other factors involved in the relationship between $H$. pylori and gastric cancer}

Only a small proportion of subjects with $H$. pylori infection harbor clinical gastric cancer during their lifetimes, whereas other subjects do not, although they are infected with $H$. pylori. Factors other than $H$. pylori infection seem to determine whether subjects with $H$. pylori harbor gastric cancer during their lifetimes. Among factors involved with $H$. pylori infection, a host factor and a factor related to the virulence of $H$. pylori have attracted attention. The former is an interleukin-1 polymorphism, which is related to the severity of inflammation in the stomach when $H$. pylori infection occurs. The latter is the cytotoxin-associated antigen, CagA, produced by some strains of $H$. pylori.

In addition to these factors, the distribution of gastritis provoked by $H$. pylori, as well as dietary factors, have been confirmed to influence the relationship between $H$. pylori and gastric cancer.

\section{Interleukin-1 $\beta$ (IL-1 $\beta)$ polymorphism}

$H$. pylori increases IL-1 $\beta$ production, which amplifies the inflammatory response to $H$. pylori infection $[59,60]$ and inhibits gastric acid secretion [61]. The excess production of IL-1 $\beta$ depends on the presence of an IL-1 $\beta$ polymorphism. H. pylori-positive individuals who had haplotypes that upregulated IL-1 $\beta$ production, such as $I L 1-\beta-511 \mathrm{~T} / 31 \mathrm{C}$ and $I L-1 R N^{*} 2$, showed an increased risk for gastric cancer $[62,63]$. In other words, the effect of $H$. pylori infection on the risk for gastric cancer depends on the severity of inflammation, which is determined by genetic factors. These findings may be one explanation for the findings that only a small proportion of $H$. pylori infections cause gastric cancer. In the near future, it is to be hoped that the precise effect of ILI$\beta$-31 haplotypes on the risk of gastric cancer will be established.

\section{CagA and gastric cancer}

H. pylori strains are divided into two groups; strains with and without a cag pathogenicity island. Strains with the cag pathogenicity island produce $\mathrm{CagA}$, a cytotoxinassociated antigen [64], and have stronger virulence than strains without a cag pathogenicity islands $[65,66]$. When $H$. pylori infection occurs, with a strain that produces CagA, CagA antibody is produced in the serum [67] and can be measured with an immunoassay [68].

Several serological studies have assessed the relationship between gastric cancer and CagA-positive or -negative strains of $H$. pylori. Two studies conducted in the United States have shown that a CagA-positive strain was more strongly related to intestinal type gastric cancer than a CagA-negative strain, while CagA was not associated with a risk for diffuse type gastric cancer $[69,70]$. A Japanese study showed a positive relationship between CagA and gastric cancer; in that study, the control subjects were those who underwent gastric endoscopy. In a young Japanese population (those 
under 40 years of age), CagA was not related to diffuse type gastric cancer, and it showed an odds ratio of 1.0 for intestinal type cancer, although the sample size was too small for a definitive conclusion [71]. In China, no difference in seroprevalence for antibody against CagA antigen was observed between gastric cancer patients and asymptomatic subjects [72]. A Brazilian study, in which the cagA gene was detected by polymerase chain reaction, showed that cagA-positive strains of $H$. pylori entailed a stronger risk for both intestinal and diffuse types of gastric cancer than cagA-negative strains [73]. Thus, results regarding the effect of CagA on the risk for gastric cancer have been controversial. A recent study has revealed that CagA protein is inserted into the host cell by $H$. pylori [74]; the biological effect of $\mathrm{CagA}$ is attracting the attention of many researchers. Further epidemiological studies are needed to determine conclusively whether the CagA status of $H$. pylori strains is related to the risk for gastric cancer.

\section{Chronic gastritis and intestinal metaplasia provoked by $\mathrm{H}$. pylori and risk of gastric cancer}

Chronic gastritis and intestinal metaplasia are thought to be precancerous lesions $[75,76]$. Gastritis provoked by $H$. pylori is also related to the risk for gastric cancer [77]. Recent case-control and cohort studies have shown that individuals with chronic gastritis in the corpus, including pangastritis, have a higher risk for gastric cancer than those with antrum-predominant gastritis [78-80], and those with intestinal metaplasia have an even higher risk $[79,80]$.

\section{Dietary factors and gastric cancer}

It is well-known that the intake of fresh vegetables reduces the risk for gastric cancer, and vitamin $\mathrm{C}$ (ascorbic acid) is thought to be the major preventive factor [8188]. Beta-carotene is also thought to be a preventive factor. The eradication of $H$. pylori improves the secretion of vitamin C into gastric juice [89]; that is, H. pylori reduces this secretion. $H$. pylori also reduces the systemic availability of dietary vitamin C [90]. From results of a retrospective study, it was inferred that a daily intake of fresh fruits and vegetables prevented the transition from gastritis to intestinal metaplasia, while smoking accelerated [91]. An intervention study has shown that the eradication of $H$. pylori, and supplements of vitamin $\mathrm{C}$ and beta-carotene brought about the regression of cancer precursor lesions [92]. A cohort study has revealed that individuals with a low level of serum vitamin $\mathrm{C}$ have a higher risk for gastric cancer, although serum beta-carotene concentration was not related to the risk [93]. Thus, although no direct proof has been obtained yet, the studies to date strongly indi- cate the preventive effect of vitamin $\mathrm{C}$ against carcinogenesis in the stomach associated with $H$. pylori infection. On the other hand, the effect of beta-carotene in this regard seems to be unclear.

\section{Negative relationship between $\boldsymbol{H}$. pylori and gastric cardia or esophageal adenocarcinoma}

Several studies have shown that $H$. pylori, especially CagA-positive strains, exert a protective effect against gastric cardia and esophageal adenocarcinoma [94,95], although a few contradictory results have been obtained [96]. Inflammation provoked by $H$. pylori inhibits gastric secretion, and prevents gastroesophageal reflux disease (GERD) [97,98]. GERD creates lesions in the esophageal mucosa known as Barrett's esophagus. Barrett's esophagus is positively related to, and is thought to be, a precancerous lesion of esophageal adenocarcinoma [99].

There is a remarkable difference between the United States and Japan in the incidence of esophageal adenocarcinoma. In the United States, adenocarcinoma accounts for not less than $50 \%$ of esophageal cancers [100], while in Japan it accounts for, at most, $3 \%$. Therefore, because of this low incidence, no Japanese study has yet assessed the relationship between H. pylori status and esophageal adenocarcinoma. In studies showing a negative relationship between $H$. pylori status and esophageal adenocarcinoma, the areas from which the population were drawn had a low prevalence of $H$. pylori. In Japan, the prevalence of $H$. pylori is still high among those aged over 50 years, who are at considerable risk for esophageal cancer. Those with genetic or lifestyle factors that would cause esophageal adenocarcinoma without $H$. pylori infection may not have the disease during their lifetime because they have $H$. pylori infection. In the future, esophageal adenocarcinoma is expected to increase in the Japanese population, because the prevalence of $H$. pylori is decreasing. In the United States, both esophageal and gastric cardia adenocarcinoma increased from 1975 to 1995 [100,101].

Results of studies in Japan have contradicted the findings of a negative relationship between gastric cardia cancer and $H$. pylori infection reported in the United States. Our study, in subjects under 40 years of age, has shown that proximal cancer, the main lesion of which is within the proximal third of the stomach, is positively related to $H$. pylori infection, although the odds ratio for proximal cancer was smaller than that for distal cancer [31,71]. Calculations with data from another study, in which the subjects were aged 20-69 [32], has given similar results. An explanation for the controversial results is that two types of cancers appear in the proximal region of the stomach; one positively related 
to, and the other negatively related to, $H$. pylori infection. The former type may be prevalent in areas with a high prevalence of $H$. pylori infection, while the latter type may be prevalent in areas with a low prevalence of H. pylori infection. As mentioned above, Barrett's esophagus is frequent in individuals without $H$. pylori infection and is thought to be a precancerous lesion of esophageal adenocarcinoma or cardia cancer. In subjects without Barrett's esophagus, another type of intestinal metaplasia is observed around the cardia [102]. This may be a precancerous lesion of gastric cancer that is positively related to $H$. pylori infection. In accordance with the decrease in $H$. pylori prevalence in Japan, the type of cardia cancer with a positive relationship to $H$. pylori infection may decrease, and the type with a negative relationship to $H$. pylori infection may increase, so that cardia cancer in Japan will show a negative relationship to $H$. pylori infection.

\section{Could an increase in esophageal adenocarcinoma be a drawback in the employment of a preventive strategy against gastric cancer that involves the eradication of $\mathrm{H}$. pylori?}

An increase in esophageal adenocarcinoma is expected if the prevalence of $H$. pylori decreases. The eradication of $H$. pylori may therefore elevate the risk for esophageal adenocarcinoma, and an anticipated increase in esophageal adenocarcinoma could be a drawback in the employment of preventive strategies against gastric cancer involving the eradication of $H$. pylori.

In Table 4, esophageal and gastric cancer mortality in Japan, the United States, and the United Kingdom is shown [103]. Japan shows a higher gastric cancer mortality than these two other countries. The United Kingdom shows a higher esophageal cancer mortality than Japan, but the difference is small compared with that in gastric cancer mortality. Esophageal cancer mortality in the United States is lower than that in Japan. It is expected that the eradication of $H$. pylori will cause both a decrease in gastric cancer and an increase in esophageal adenocarcinoma, and, in terms of numbers, the former is much larger than the latter. Thus, judging from this comparison of mortality among these countries, eradication of $H$. pylori may have the effect of decreasing the total number of cancer patients.

Table 4. Esophageal and gastric cancera mortality

\begin{tabular}{lrrrrrr}
\hline & \multicolumn{3}{c}{ Stomach } & \multicolumn{3}{c}{ Esophagus } \\
\hline Japan & Male & 34.5 & Female & 15.2 & Male 7.0 & Female 1.0 \\
USA & Male & 5.1 & Female & 2.3 & Male 4.7 & Female 1.1 \\
UK & Male & 12.4 & Female & 5.1 & Male 7.8 & Female 3.2
\end{tabular}

a 1988-1992, mortality per 100000 person-years, age-adjusted (From [103])
However, the critical time of $H$. pylori in gastric carcinogenesis is still unclear. It has been argued that $H$. pylori eradication often causes gastroesophageal reflux, so that the eradication predisposes to the development of Barrett's esophagus; however, the precise time period during which $H$. pylori exerts its inhibitory effect on esophageal carcinogenesis is not clear. If the critical time of $H$. pylori in gastric carcinogenesis were in early childhood and if $H$. pylori exerted its inhibitory effect on esophageal cancer even in adulthood, eradication in adulthood would elevate the risk for esophageal cancer without showing any decrease in the risk for gastric cancer. In the creation of preventive strategies against gastric cancer, these problems are very important, and they should be solved by well-designed clinical trials.

\section{References}

1. Warren JR, Marshall BJ. Unidentified curved bacilli on gastric epithelium in active chronic gastritis. Lancet 1983;1:1273-5.

2. Marchildon PA, Coita LM, Zamaniyan FZ, Peacock JS, Graham GY. Evaluation of three commercial enzyme immunoassays compared with the $13 \mathrm{C}$ urea breath test for detection of Helicobacter pylori infection. J Clin Microbiol 1996;34:1147-52.

3. Roosendaal R, Kuipers EJ, Buitenwerf J, Meuwissen CUSGM, van Kamp GJ, Vandenbroucke-Grauls CMJE, et al. Helicobacter pylori and the birth cohort effect: evidence of a continuous decrease of infection rates in childhood. J Gastroenterol 1997;92:1480-2.

4. Asaka M, Kimura T, Kudo M, Takeda H, Mitani S, Miyazaki T, et al. Relationship between Helicobacter pylori and serum pepsinogen in an asymptomatic Japanese population. Gastroenterology 1992;102:760-6.

5. Miyaji H, Azuma T, Ito S, Abe Y, Gejyo F, Hashimoto N, et al. Helicobacter pylori infection occurs via close contact with infected individuals in early childhood. J Gastroenterol Hepatol 2000;15:257-62.

6. Kikuchi S, Kurosawa M, Sakiyama T. Helicobacter pylori risk associated with sibship size and family history of gastric diseases in Japanese adults. Jpn J Cancer Res 1998;89:1109-12.

7. Webb PM, Knight T, Greaves S, Wilson A, Newell DG, Elder J, et al. Relation between infection with Helicobacter pylori and living conditions in childhood: evidence for person to person transmission in early life. BMJ 1994;308:750-3.

8. Sipponen P, Kousnen TU, Samloff IM, Heinonen OP, Siurala M. Rate of Helicobacter pylori acquisition among Finnish adults. Scand J Gastroenterol 1996;31:229-32.

9. Kurosawa M, Kikuchi S, Inaba Y, Ishibashi T, Kobayashi F. Helicobacter pylori infection, gastritis and gastric cancer. J Gastroenterol Hepatol 2000;15:1382-5.

10. Krumbiegel P, Boeckler D, Lehmann I, Jorks S, Fritz G, Babel $\mathrm{W}$, et al. Is water a source of $H$. pylori infection in central Europe (abstract)? Gut 2000; Suppl 1:46.

11. Olmos JA, Rios H, Higa R. Prevalence of Helicobacter pylori infection in Argentina: results of a nationwide epidemiologic study. J Clin Gastroenterol 2000;31:33-7.

12. The Eurogust Study Group. An international association between Helicobacter pylori infection and gastric cancer. Lancet 1993;341:1359-62.

13. Young KA, Allaker RP, Hardie JM. Morphological analysis of Helicobacter pylori from gastric biopsies and dental plaque by scanning electron microscopy. Oral Microbiol Immunol 2001;16: 178-81. 
14. Parsonnet J, Shmuely H, Haggerty T. Fecal and oral shedding of Helicobacter pylori from healthy infected adults. JAMA 1999;282:2240-5.

15. Rudi J, Toppe H, Marx N, Zuna I, Theilmann L, Stremmel W, et al. Risk of infection with Helicobacter pylori and hepatitis A virus in different groups of hospital workers. Am J Gastroenterol 1997;92:258-62.

16. Luzza F, Imeneo M, Maletta M, Paluccio G, Giancotti A, Perticone F, et al. Seroepidemiology of Helicobacter pylori infection and hepatitis $\mathrm{A}$ in a rural area: evidence against a common mode of transmission. Gut 1977;41:164-8.

17. Furuta T, Kamata T, Takashima M, Futami H, Arai H, Hanai H, et al. Study of transmission routes of Helicobacter pylori in relation to seroprevalence of hepatitis A virus. J Clin Microbiol 1997;35:1891-3.

18. Luzza F, Mancuso M, Imeneo M, Contaldo A, Giancotti L, Pensabene L, et al. Evidence favouring the gastro-oral route in the transmission of Helicobacter pylori infection in children. Eur J Gastroenterol Hepatol 2000;12:623-7.

19. Forman D, Sitas F, Newell DG, Stacey AR, Boreham J, Peto R, et al. Geographic association of Helicobacter pylori antibody prevalence and gastric cancer mortality in rural China. Int $\mathbf{J}$ Cancer 1990;46:608-11.

20. Fukao A, Komatsu S, Tsubono Y, Hisamichi S, Ohori H, Kizawa $\mathrm{T}$, et al. Helicobacter pylori infection and chronic atrophic gastritis among Japanese blood donors: a cross-sectional study. Cancer Causes Control 1993;4:307-12.

21. Tsugane S, Kabuto M, Imai H, Gey F, Tei Y, Hanaoka T, et al. Helicobacter pylori, dietary factors, and atrophic gastritis in five Japanese populations with different gastric cancer mortality. Cancer Causes Control 1993;4:297-305.

22. Forman D, Newell DG, Fullerton F, Yarnell JWG, Stacey AR, Wald N, et al. Association between infection with Helicobacter pylori and risk of gastric cancer. BMJ 1991;302:1302-5.

23. Nomura A, Stemmermann GN, Chyou P, Kato I, Perez-Perez GI, Blaser MJ. Helicobacter pylori infection and gastric carcinoma among Japanese Americans in Hawaii. N Engl J Med 1991;325:1132-6.

24. Parsonnet J, Friedman GD, Vandersteen DP, Chang Y, Volgelman JH, Orentreich N, et al. Helicobacter pylori infection and risk of gastric carcinoma. N Engl J Med, 1991;325:1127-31.

25. Webb PM, Yu MC, Forman D, Henderson BE, Newell DG, Yuan JM, et al. An apparent lack of association between Helicobacter pylori infection and risk of gastric cancer in China. Int J Cancer 1996;67:603-7.

26. Lin JT, Wang LY, Wang JT, Wang TH, Yang CS, Chen CJ. A nested case-control study on the association between Helicobacter pylori infection and gastric cancer risk in a cohort of 9775 men in Taiwan. Anticancer Res 1995;15:603-6.

27. Watanabe Y, Kurata JH, Mizuno S, Mukai M, Inokuchi H, Miki $\mathrm{K}$, et al. Helicobacter pylori infection and gastric cancer. Dig Dis Sci 1997;42:1383-7.

28. Aromaa A, Kosunen TU, Knekt P, Maatela J, Teppo L, Heinonen OP, et al. Circulating anti-Helicobacter pylori immunoglobulin A antibodies and low serum pepsinogen I level are associated with increased risk of gastric cancer. Am J Epidemiol 1996;2:142-9.

29. Hansson LE, Engstrand L, Nyren O, Evand DJ Jr, Lindgren A, Bergstrom R, et al. Helicobacter pylori infection: independent risk indicator of gastric adenocarcinoma. Gastroenterology 1993;105:1098-103.

30. Asaka M, Kimura T, Kato M, Kudo M, Miki K, Ogoshi K, et al. Possible role of Helicobacter pylori infection in early gastric cancer development. Cancer 1994;73:2691-4.

31. Kikuchi S, Wada O, Nakajima T, Nishi T, Kobayashi M, Konishi $\mathrm{T}$, et al. Serum anti-Helicobacter pylori antibody and gastric carcinoma among young adults. Cancer 1995;75:2789-93.

32. Kikuchi S, Nakajima T, Kobayashi O, Yamazaki T, Kikuchi M, Mori $\mathrm{K}$, et al. Effect of age on the relationship between gastric cancer and Helicobacter pylori. Jpn J Cancer Res 2000;91: 774-9.

33. Rudi J, Muller M, von Herbay A, Zuna I, Raedsch R, Stremmel W, et al. Lack of association of Helicobacter pylori seroprevalence and gastric cancer in a population with low gastric cancer incidence. Scand J Gastroenterol 1995;30:95863.

34. Fukuda H, Saito D, Hayashi S, Hisai H, Ono H, Yoshida S, et al. Helicobacter pylori infection, serum pepsinogen level and gastric cancer: a case-control study in Japan. Jpn J Cancer Res 1995;86: 64-71.

35. Masci E, Viale E, Freschi M, Porcellati M, Tittobello A. Precancerous gastric lesions and Helicobacter pylori. Hepatogastroenterology 1996;43:854-8.

36. Kuipers EJ, Uyterlinde AM, Pena AS, Roosendaal R, Pals G, Nelis GF, et al. Long-term sequelae of Helicobacter pylori gastritis. Lancet 1995;345:1525-8.

37. Veldhuyzen van Zanten SJO, Pollak T, Best LM, Bezanson GS, Marrie T. Increasing prevalence of Helicobacter pylori infection with age: continuous risk of infection in adults rather than cohort effect. J Infect Dis 1994;169:434-7.

38. Kikuchi S. Change of serum Helicobacter pylori antibody and pepsinogens during a 9-year span in healthy Japanese (abstract). Gut 2000;47:A49.

39. Wee A, Kang JY, Teh M. Helicobacter pylori and gastric cancer: correlation with gastritis, intestinal metaplasia, and tumour histology. Gut 1992;33:1029-32.

40. Klaamas K, Held M, Wadstrom T, Lipping A, Kurtenkov O. IgG immune response to Helicobacter pylori antigens in patients with gastric cancer as defined by ELISA and immunoblotting. Int $\mathbf{J}$ Cancer 1996;67:1-5.

41. Tsukuma H, Mishima T, Oshima A. Prospective study of "EARLY" gastric cancer. Int J Cancer 1983;31:421-6.

42. Sakagami T, Dixon M, O'Rourke J, Howlett R, Alderuccio F, Vella J, et al. Atrophic gastric changes in both Helicobacter felis and Helicobacter pylori infected mice are host dependent and separate from antral gastritis. Gut 1996;39:639-48.

43. Karnes WE Jr, Samloff IM, Siurala M, Kekki M, Sipponen P, Kim SWR, et al. Positive serum antibody and negative tissue staining for Helicobacter pylori in subjects with atrophic body gastritis. Gastroenterology 1991;101:167-74.

44. Matsukura N, Suzuki K, Kawachi T, Aoyagi M, Sugimura T, Kitaoka H, et al. Distribution of marker enzymes and mucin in intestinal metaplasia in human stomach and relation of complete and incomplete types of intestinal metaplasia to minute gastric carcinoma. J Natl Cancer Inst 1980;65:231-40.

45. Parsonnet J, Vandersteen D, Goates J, Sibley RK, Pritikin, J Chang Y. Helicobacter pylori infection in intestinal- and diffusetype gastric adenocarcinomas. J Natl Cancer Inst 1991;83:640-3.

46. Tatsuta M, Iishi H, Okuda S, Taniguchi H, Yokota Y. The association of Helicobacter pylori with differentiated-type early gastric cancer. Cancer 1993;72:1841-5.

47. Huang JQ, Sridhar S, Chen Y, Hunt RH. Meta-analysis of the relationship between Helicobacter pylori and gastric cancer. Gastroenterology 1998;114:1169-79.

48. Endo S, Ohkusa T, Saito Y, Fujiki K, Okayasu I, Sato C. Detection of Helicobacter pylori infection in early stage gastric cancer. Cancer 1995;75:2203-8.

49. Oshima A. A critical review of cancer screening programs in Japan. Int J Technol Assess Health Care 1994;10:346-58.

50. Weed DL. On the use of causal criteria. Int J Epidemiol 1997;26: 1137-41.

51. Watanabe T, Tada M, Nagai H, Sasaki S, Nakao M. Helicobacter pylori infection induces gastric cancer in Mongolian gerbils. Gastroenterology 1998;115:642-8.

52. Tokieda M, Honda S, Fujioka T, Nasu M. Effect of Helicobacter pylori infection on the N-methyl- $\mathrm{N}^{\prime}$-nitro-N-nitrosoguanidineinduced gastric carcinogenesis in Mongolian gerbils. Carcinogenesis 1999;20:1261-6. 
53. Shimizu N, Inada K, Nakanishi $\mathrm{H}$, Tsukamoto $\mathrm{T}$, Ikehara $\mathrm{Y}$, Kaminishi $\mathrm{M}$, et al. Helicobacter pylori infection enhances glandular stomach carcinogenesis in Mongolian gerbils treated with chemical carcinogens. Carcinogenesis 1999;20:66976.

54. Shimizu N, Ikehara Y, Inada K, Nakanishi H, Tsukamoto T, Nozaki K, et al. Eradication diminishes enhancing effects of Helicobacter pylori infection on glandular stomach carcinogenesis in Mongolian gerbils. Cancer Res 2000;60:1512-14.

55. Mizuno S, Akiba S. Smoking and lung cancer mortality in Japanese men: estimates for dose and duration of cigarette smoking based on the Japan vital statistics data. Jpn J Cancer Res 1989;80:727-31.

56. Mizuno S, Akiba S, Hirayama T. Lung cancer risk comparison among male smokers between the "Six-prefecture Cohort" in Japan and the British physicians cohort. Jpn J Cancer Res 1989;80:1165-70.

57. Blaser MJ, Chyou PH, Nomura A. Age at establishment of Helicobacter pylori infection and gastric carcinoma, gastric ulcer and duodenal ulcer risk. Cancer Res 1995;55:562-5.

58. Uemura N, Mukai T, Okamoto S, Yamaguchi S, Mashiba H, Taniyama K, et al. Effect of Helicobacter pylori eradication on subsequent development of cancer after endoscopic resection of early gastric cancer. Cancer Epidemiol Biomarkers Prev 1997;6: 639-42.

59. Noach LA, Bosma NB, Jansen J, Hoek FJ, van Deventer SJ, Tytgat GN. Mucosal tumor necrosis factor-alpha, interleukin-1 beta, and interleukin-8 productions in patients with Helicobacter pylori infection. Scand J Gastroenterol 1994;29:425-9.

60. Basso D, Scrigner M, Toma A, Navaglia F, Di Mario F, Rugge $\mathrm{M}$, et al. Helicobacter pylori infection enhances mucosal interleukin-1 beta, interleukin-6, and the soluble receptor of interleukin-2. Int J Clin Lab Res 1996;26:207-10.

61. Beales IL, Calam J. Interleukin-1 beta and tumor necrosis factor alpha inhibit acid secretion in cultured rabbit parietal cells by multiple pathways. Gut 1998;42:227-34.

62. El-Omar EM, Carrington M, Chow W, Mccoll KEL, Bream JH, Young HA, et al. Interleukin-1 polymorphisms associated with increased risk of gastric cancer. Nature 2000;404:398402.

63. El-Omar EM, Carrington M, Chow W, Mccoll KEL, Bream JH, Young HA, et al. Correction of "Interleukin-1 polymorphisms associated with increased risk of gastric cancer. Nature 2000;404:398-402". Nature 2001;412:99.

64. Tummuru MR, Cover TL, Blaser MJ. Cloning and expression of a high-molecular-mass major antigen of Helicobacter pylori: evidence of linkage to cytotoxin production. Infect Immunol 1993;61:1799-809.

65. Crabtree JE, Taylor JD, Wyatt JI, Heatley RV, Shallcross TM, Tompkins DS, et al. Mucosal IgA recognition of Helicobacter pylori $120 \mathrm{kDa}$ protein, peptic ulceration, and gastric pathology. Lancet 1991;338:332-5.

66. Covacci A, Censini S, Bugnoli M, Petracca R, Burroni D, Macchia G, et al. Molecular characterization of the $128-\mathrm{kDa}$ immunodominant antigen of Helicobacter pylori associated with cytotoxicity and duodenal ulcer. Proc Natl Acad Sci USA 1993;90:5791-5.

67. Beals ILP, Crabtree JE, Scunes D, Covacci A, Calam J. Antibodies to CagA protein are associated with gastric atrophy in Helicobacter pylori infection. Eur J Gastroentrol Hepatol 1996;8:645-9.

68. Cover TL, Glupczynski Y, Lage AP, Burette A, Tummuru MR, Perez-Perez GI, et al. Serologic detection of infection with cagA + Helicobacter pylori strains. J Clin Microbiol 1995;33: 1496-500.

69. Blaser MJ, Perez-Perez GI, Kleanthous H, Cover TL, Peek RM, Chyou PH, et al. Infection with Helicobacter pylori strains possessing CagA is associated with an increased risk of developing adenocarcinoma of the stomach. Cancer Res 1995;55:2111-15.
70. Parsonnet J, Friedman GD, Orentreich N, Vogelman H. Risk for gastric cancer in people with CagA positive or CagA negative Helicobacter pylori infection. Gut 1997;40:297-301.

71. Kikuchi S, Crabtree JE, Forman D, Kurosawa M, the Research Group on Prevention of Gastric Carcinoma among Young Adults. Association between infections with CagA-positive or -negative strains of Helicobacter pylori and risk for gastric cancer in young adults. Am J Gastroenterol 1999;94:3455-9.

72. Mitchell HM, Hazell SL, Li YY, Hu PG. Serological response to specific Helicobacter pylori antigens: antibody against CagA antigen is not predictive of gastric cancer in a developing country. Am J Gastroenterol 1996;91:1785-8.

73. Queiroz DMM, Mendes EN, Rocha GA, Oliveira AMR, Oliveira CA, Magalhaes PP, et al. cagA-Positive Helicobacter pylori and risk for developing gastric carcinoma in Brazil. Int $\mathbf{J}$ Cancer 1998;78:135-9.

74. Segal ED, Cha J, Lo J, Falkow S, Tompkins LS. Altered states: involvement of phosphorylated CagA in the induction of host cellular growth changes by Helicobacter pylori. Proc Natl Acad Sci USA 1999;96:14559-64.

75. Nakahara K. Special features of intestinal metaplasia and its relation to early gastric carcinoma in man: observation by a method in which leucine aminopeptidase activity is used. J Natl Cancer Inst 1978;61:693-701.

76. Correa P, Cuello C, Duque E, Burbano LC, Garcia FT, Bolanos $\mathrm{O}$, et al. Gastric cancer in Colombia. III. Natural history of precursor lesions. J Natl Cancer Inst 1976;57:1027-35.

77. Sipponen P, Kosunen TU, Valle J, Riihela M, Seppala K. Helicobacter pylori infection and chronic gastritis in gastric cancer. J Clin Pathol 1992;45:319-23.

78. Miehlke S, Hackelsberger A, Meining A, Hatz R, Lehn N, Malfertheiner P, et al. Severe expression of corpus gastritis is characteristic in gastric cancer patients infected with Helicobacter pylori. Br J Cancer 1998;78:263-6.

79. Fukuda S, Tanaka M, Soma Y, Shimoyama T, Mikami T, Crabtree JE, et al. Gastritis and gastric cancer: histological analysis of gastritis and Helicobacter pylori infection in patients with early gastric cancer: a case-control study. J Gastroenterol Hepatol 2000;15:1370-6.

80. Uemura $\mathrm{N}$, Okamoto $\mathrm{S}$, Yamamoto $\mathrm{S}$, Matsumura $\mathrm{N}$, Yamaguchi S, Yamakido M, et al. Helicobacter pylori infection and the development of gastric cancer. N Engl J Med 2001;345: 784-9.

81. Trichopoulos D, Ouranos G, Day NE, Tzonou A, Manousos O, Papadimitriou C, et al. Diet and cancer of the stomach: a casecontrol study in Greece. Int J Cancer 1985;36:291-7.

82. Correa P, Fontham E, Pickle LW, Chen V, Lin YP, Haenszel W. Dietary determinants of gastric cancer in south Louisiana inhabitants. J Natl Cancer Inst 1985;75:645-54.

83. Vecchia C, Negri E, Decarli A, D’Avanzo B, Franceschi S. A case-control study of diet and gastric cancer in northern Italy. Int J Cancer 1987;40:484-9.

84. Kono S, Ikeda M, Tokudome S, Kuratsune M. A case-control study of gastric cancer and diet in northern Kyushu, Japan. Jpn J Cancer Res 1988;79:1067-74.

85. Demirer T, Icli F, Uzunalimoglu O, Kucuk O. Diet and stomach cancer incidence. A case-control study in Turkey. Cancer 1990;65:2344-8.

86. Chyou PH, Nomura AM, Hankin JH, Stemmermann GN. A case-cohort study of diet and stomach cancer. Cancer Res 1990;50:7501-4.

87. Ramon JM, Serra L, Cerdo C, Oromi J. Dietary factors and gastric cancer risk. A case-control study in Spain. Cancer 1993;71:1731-5.

88. Hansson LE, Nyren O, Bergstrom R, Wolk A, Lindgren A, Baron J, et al. Diet and risk of gastric cancer. A populationbased case-control study in Sweden. Int J Cancer 1993;55:181-9.

89. Sobala GM, Schorah CJ, Shires S, Lynch DA, Gallacher B, Dixon MF, et al. Effect of eradication of Helicobacter pylori 
on gastric juice ascorbic acid concentrations. Gut 1993;34:103841.

90. Woodward M, Tunstall-Pedoe H, McColl K. Helicobacter pylori infection reduces systemic availability of dietary vitamin C. Eur J Gastroenterol Hepatol 2001;13:233-7.

91. Jedrychowski W, Popiela T, Drews M, Gabryelewicz A, Marlicz $\mathrm{K}$, Misiunia $\mathrm{P}$, et al. Effect of Helicobacter pylori infection, smoking and dietary habits on the occurrence of antrum intestinal metaplasia. Clinico-epidemiological study in Poland. Pol J Pathol 1999;50:289-95.

92. Correa P, Fontham ET, Bravo JC, Bravo LE, Ruiz B, Zarama G, et al. Chemoprevention of gastric dysplasia: randomized trial of antioxidant supplements and anti-Helicobacter pylori therapy. J Natl Cancer Inst 2000;92:1881-8.

93. You WC, Zhang L, Gail MH, Chang YS, Liu WD, Ma JL, et al. Gastric dysplasia and gastric cancer: Helicobacter pylori, serum vitamin C, and other risk factors. J Natl Cancer Inst 2000;92: 1607-12.

94. Chow WH, Blaser MJ, Blot WJ, Gammon MD, Vaugan TL, Risch HA, et al. An inverse relation between cagA+ strains of Helicobacter pylori infection and risk of esophageal and gastric cardia adenocarcinoma. Cancer Res 1998;588-90.

95. Weston AP, Badr AS, Topalovski M, Cherian R, Dixon A, Hassanein RS. Prospective evaluation of the prevalence of gastric Helicobacter pylori infection in patients with GERD, Barrett's esophagus, Barrett's dysplasia, and Barrett's adenocarcinoma. Am J Gastroenterol 2000;95:387-94.
96. Oberg S, Peters JH, Nigro JJ, Theisen J, Hagen JA, DeMeester $\mathrm{SR}$, et al. Helicobacter pylori is not associated with the manifestations of gastroesophageal reflux disease. Arch Surg 1999;134:722-6.

97. Vaezi MF, Falk GW, Peek RM, Vicari JJ, Goldblum JR, PerezPerez GI, et al. CagA-positive strains of Helicobacter pylori may protect against Barrett's esophagus. Am J Gastroenterol 2000; 95:2206-11.

98. Loffeld RJ, Werdmuller BF, Kuster JG, Perez-Perez GI, Blaser MJ, Kuipers EJ. Colonization with cagA-positive Helicobacter pylori strains inversely associated with reflux esophagitis and Barrett's esophagus. Digestion 2000;62:95-9.

99. Falk GW. Gastroesophageal reflux disease and Barrett's esophagus. Endoscopy 2001;33:109-18.

100. Devesa SS, Blot WJ, Fraumeni JF Jr. Changing patterns in the incidence of esophageal and gastric carcinoma in the United States. Cancer 1998;83:2049-53.

101. Salvan-Harman JC, Cady B, Nikulasson S, Khettry U, Stone MD, Lavin P. Shifting proportions of gastric adenocarcinomas. Arch Surg 1994;129:381-9.

102. Hackelsberger A, Gunther T, Schultze V, Manes G, DominguezMunoz J-E, Roessner A, et al. Intestinal metaplasia at the gastro-oesophageal junction: Helicobacter pylori gastritis or gastro-oesophageal reflux disease? Gut 1998;43:17-21.

103. Tominaga S, Kuroishi T, Aoki K, editors. Cancer mortality statistics in 33 countries (International Union Against Cancer [UICC]). Nagoya: Roppo Shuppan; 1998. p 1953-92. 